\title{
The steam locomotive makes a comeback: A new solution to staged single-ventricle palliation?
}

\author{
William M. DeCampli, MD, PhD
}

See related article on pages 699-705.

Achieving long-term survival and good quality of life for patients with single-ventricle circulations remains one of the greatest challenges in the field of congenital heart disease. Much of the mortality occurs during the period of "shunt dependency." The concept of avoiding this period by allowing the bidirectional Glenn shunt to be performed during the neonatal period has always been appealing, but attempts to do so have been unsuccessful.

In the current issue of the Journal, Esmaily-Moghadam and coworkers ${ }^{1}$ propose to combine the bidirectional Glenn shunt and placement of a restrictive systemic-to-pulmonary shunt during the stage 1 operation. On the surface, this idea seems counterproductive, as it would only serve to further raise superior vena caval (SVC) pressure, with its attendant risks in the neonatal period.

Esmaily-Moghadam and coworkers' approach, however, is more sophisticated than that. They seek to turn the shunt into a forward-directed, high-velocity jet that adds energy and momentum to the Glenn flow without a significant rise in SVC pressure. The mechanism is called the ejector jet. The phenomenon was instrumental in the design of the steam locomotive and has had widespread industrial applications.

To understand the ejector jet, consider Figure $1 .^{2}$ Two fluid compartments ( $a$ and $b$ ) are connected by a pipe of area $A_{2}$. If the pressure in $a\left(P_{A}\right)$ is greater than the pressure in $b\left(P_{B}\right)$, the fluid flows left to right. In turn, imagine that fluid in compartment $b$ must empty at a certain rate $(Q)$ through a resistive orifice into a reservoir. This flow rate must be maintained by sufficiently large $\mathrm{P}_{\mathrm{B}}$. Whatever $\mathrm{P}_{\mathrm{B}}$ is, $\mathrm{P}_{\mathrm{A}}$ must be even greater without the ejector jet.

Now enter the ejector jet. It is powered by a pump that draws a relatively small amount of fluid (density $\rho$, rate $Q_{j}$ ) from compartment $a$ and ejects it at high velocity into

From The Heart Center at Arnold Palmer Hospital for Children, Orlando, Fla; and the College of Medicine, University of Central Florida, Orlando, Fla.

Disclosures: Author has nothing to disclose with regard to commercial support.

Received for publication Nov 20, 2014; accepted for publication Nov 22, 2014; available ahead of print Jan 25, 2015.

Address for reprints: William M. DeCampli, MD, PhD, Division of Cardiothoracic Surgery, The Heart Center at Arnold Palmer Hospital for Children, 92 W Miller St, Orlando, FL 32806 (E-mail: William.decampli@orlandohealth.com or William.decampli@ucf.edu).

J Thorac Cardiovasc Surg 2015;149:706-7

$0022-5223 / \$ 36.00$

Copyright (c) 2015 by The American Association for Thoracic Surgery

http://dx.doi.org/10.1016/j.jtcvs.2014.11.064

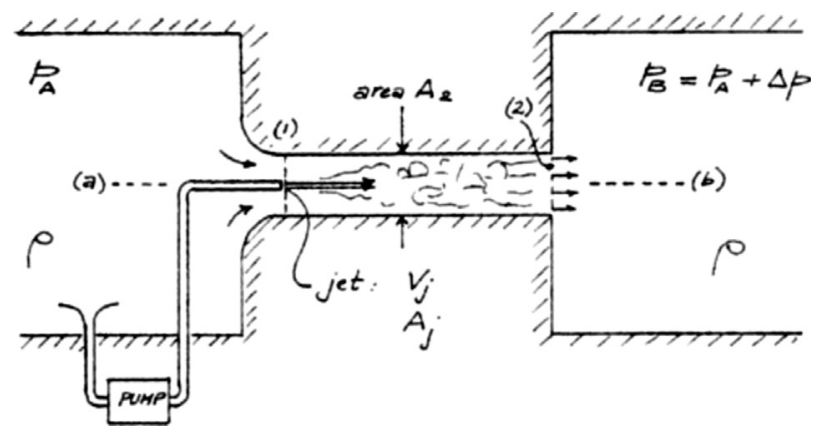

FIGURE 1. Two compartments ( $a$ and $b$ ) filled with fluid (density $\rho$ ) are connected by a pipe of cross-sectional area $A_{2}$. The ejector jet is powered by a pump that draws a relatively small amount of fluid from compartment $a$ and ejects it at high velocity $\left(V_{j}\right)$ into the pipe at position 1 through a small orifice ( $\operatorname{area} A_{j}$ ). The total flow enters compartment $b$ at position 2. $P_{A}$, Pressure in compartment $a ; P_{B}$, pressure in compartment $b ; \Delta P$; difference in pressure between compartments. Reprinted with permission. ${ }^{2}$

the pipe through a small orifice of area $A_{j}$. The jet entrains and mixes with the surrounding flow and imparts kinetic energy and momentum to it. The energized flow enters compartment $b$ and diffuses, converting its kinetic energy back into pressure. The ejector jet augments $P_{B}$ without a rise in $P_{A}$, so the flow through the resistive orifice increases without a rise in compartment a pressure. In fact, the pressure gradient $\left(\mathrm{P}_{\mathrm{B}}-\mathrm{P}_{\mathrm{A}}\right)$ can reverse, and $\mathrm{P}_{\mathrm{A}}$ may even decrease. Under certain assumptions, one finds the following equation holds:

$$
\mathrm{P}_{\mathrm{B}}-\mathrm{P}_{\mathrm{A}} \approx-(\rho / 2)\left(\mathrm{Q} / \mathrm{A}_{2}\right)^{2}+\rho \mathrm{Q}_{\mathrm{j}}^{2} / \mathrm{A}_{2} \mathrm{~A}_{\mathrm{j}}
$$

In a computational model, Esmaily-Moghadam and coworkers inserted a shunt from the innominate artery to the SVC, angled in the direction of SVC flow and narrowed at the distal end to produce a high-velocity jet. This is the ejector jet. The pump is the ventricle. They found that, relative to the baseline Glenn circulation, the ejector jet shunt augmented pulmonary blood flow by about $30 \%$ with negligible increase in ventricular volume load and an increase in SVC pressure by about $33 \%(2 \mathrm{~mm})$ for low pulmonary resistance (PVR) and 40\% (4 mm) for high PVR. They suggest that by further optimizing the configuration of the shunt they may be able to achieve pulmonary blood flow and SVC pressure acceptable in the neonatal period, allowing the Glenn shunt to be performed with the stage 1 palliation.

As Esmaily-Moghadam and coworkers admit, however, there are still problems in designing the perfect ejector jet and making it function in the neonate. In the industrial 
world, even the "optimal" ejector jet is typically inefficient-about $30 \%$ to $35 \%$. It is very sensitive to configuration. With anatomic and surgical restrictions, the efficiency might be considerably less and manifest as excessive SVC pressure, defeating the original intent of the operation. Indeed, Esmaily-Moghadam and coworkers did not find a model that actually decreases Glenn (SVC) pressure. Furthermore, the mechanism must work under conditions of elevated PVR and large variations in PVR, which influence SVC pressure. Any sustained elevation in SVC pressure by more than about $15 \mathrm{~mm} \mathrm{Hg}$ could jeopardize cerebral circulation during systemic hypotension, either directly or indirectly through cerebral edema, and might promote rapid venous collateralization leading to hypoxemia. These are major challenges.

There may be an equally appealing, if not more workable application of the ejector jet, that is, to the "failing Fontan." One could conceive of twin jets, fed by either the aorta or the ventricle itself, inserted at the pulmonary-venous confluence and directed toward both lung hila. It can be demonstrated that this ejector jet could transfer energy to the Fontan with a shunt less than 1.5. Working in Alain
Kassab's laboratory at the University of Central Florida, my colleagues and I have demonstrated an actual pressure decrease in the inflow ("venous") compartment simultaneous with a flow increase in the outflow ("pulmonary") of a schematic numeric model incorporating an ejector jet. We are now modeling this in a closed-loop multiscale model of the complete Fontan circulation.

The ejector jet is based on a fascinating fluid dynamical phenomenon. In the proposed applications, it taps the native energy of the heart and functions as a pump with no moving parts. In principle, it can be surgically placed and interventionally managed. The steam locomotive may make a comeback-on a very different track.

\section{References}

1. Esmaily-Moghadam M, Hsia T-Y, Marsden AL; Modeling of Congenital Hearts Alliance (MOCHA) Investigators. The assisted bidirectional Glenn: A novel surgical approach for first-stage single-ventricle heart palliation. J Thorac Cardiovasc Surg. 2015;149:699-705.

2. McKinley G, Ghoniem A, Sonin A, Hosoi A. 2.25 Advanced fluid mechanics, fall 2005. Cambridge, MA: Massachusetts Institute of Technology, MIT OpenCourseWare. Available at: http://ocw.mit.edu/courses/mechanicalengineering/2-25-advanced-fluid-mechanics-fall-2005. License: Creative Commons BY-NC-SA. Accessed November 17, 2015. 